\title{
Use of Zirconia in Dentistry: An Overview
}

\author{
Ahmed A. Madfa ${ }^{*}, 1$, Fadhel A. Al-Sanabani ${ }^{1}$, Nasser H. Al-Qudami ${ }^{2}$, Jabr S. Al-Sanabani ${ }^{3}$ and \\ Abdullah G. Amran ${ }^{3}$
}

${ }^{I}$ Department of Conservative Dentistry, Faculty of Dentistry, University of Thamar, Yemen

${ }^{2}$ Department of Pediatric Dentistry, Preventive Dentistry and Orthodontics, Faculty of Dentistry, University of Thamar, Yemen

${ }^{3}$ Department of Oral Medicine, Oral Pathology and Periodontology, Faculty of Dentistry, University of Thamar, Yemen

\begin{abstract}
Due to an increasing interest in esthetics and concerns about toxic and allergic reactions to certain alloys, zirconia was proposed as a new ceramic material in the later part of $20^{\text {th }}$ century. It has become a popular alternative to alumina as biomaterial and is being used in dental applications for fabricating endodontic posts, crown and bridge restorations and implant abutments. It has also been applied for the fabrication of esthetic orthodontic brackets. This article presents a brief history, dental applications and new methods for fabrication of zirconia improving its mechanical properties. Additionally, the bonding between zirconia and resin cements as well as conventional cementation has been discussed. The methods of the improvement of the bonding strength have also been highlighted.
\end{abstract}

Keywords: Zirconia, dentistry, alumina-zirconia nanocomposites, CAD/CAM, functionally graded concept, interfacial adhesive.

\section{INTRODUCTION}

Zircon has been known as a gem since ancient times. The name zirconium comes from the Arabic "Zargun" (golden in color) which in turn comes from the two Persian words "Zar" (Gold) and "Gun" (Color) [1]. Zirconia is a crystalline dioxide of zirconium. Zirconium oxide was first used for medical purposes in 1969 for orthopedic application. It was proposed as a new material for hip head replacement instead of titanium or alumina prostheses [2].

Due to an increasing interest in esthetics and concerns about toxic and allergic reactions to certain alloys, patients and dentists have been looking for metal-free tooth-colored restorations. Therefore, the development of new high strength dental ceramics, which appear to be less brittle, less limited in their tensile strength, and less subject to time dependent stress failure, has dominated in the later part of $20^{\text {th }}$ century. These capabilities are highly attractive in prosthetic dentistry, where strength and esthetics are paramount [3-5].

It has become a popular alternative to alumina as biomaterial and is used in dental applications for fabricating endodontic posts, crown and bridge restorations and implant abutments. It has also been applied for the fabrication of esthetic orthodontic brackets [6]. The mechanical properties of commercial yttria stabilized zirconia are given in Table $\mathbf{1}$ [1].

*Address correspondence to this author at the Department of Conservative Dentistry, Faculty of Dentistry, University of Thamar, Thamar, Yemen;

Tel: 00967-6501278; Fax: 00967-6501278;

E-mail: ahmed_um_2011@yahoo.com
Table 1. Mechanical Properties of Zirconia

\begin{tabular}{|c|c|}
\hline Mechanical Properties & Amount \\
\hline \hline Density & $6.05 \mathrm{~g} / \mathrm{cm}^{3}$ \\
\hline Hardness & $1200 \mathrm{HV}$ \\
\hline Bend strength & $900-1200 \mathrm{MPa}$ \\
\hline Compressive strength & $2000 \mathrm{MPa}$ \\
\hline Fracture toughness & $7-10 \mathrm{MPam}{ }^{1 / 2}$ \\
\hline Young's modulus & $210 \mathrm{GPa}$ \\
\hline Thermal expansion coefficient & $11 \times 10^{-6} 1 / \mathrm{K}$ \\
\hline
\end{tabular}

Zirconia is organized in three different patterns: monoclinic $(\mathrm{M})$, tetragonal $(\mathrm{T})$, and cubic $(\mathrm{C})$. Pure zirconia is monoclinic at room temperature and remains stable up to $1170^{\circ} \mathrm{C}$. Above this temperature, it transforms into tetragonal and then into cubic phase that exists up to the melting point at $2370^{\circ} \mathrm{C}$. During cooling, the tetragonal phase transforms back to monoclinic in a temperature ranging from $100^{\circ} \mathrm{C}$ to $1070^{\circ} \mathrm{C}$ [1].

\section{DENTAL APPLICATION OF ZIRCONIA}

Although many types of zirconia-containing ceramic systems are currently available [7], only three are used to date in dentistry. These are yttrium cation-doped tetragonal zirconia polycrystals (3Y-TZP), magnesium cation-doped partially stabilized zirconia (Mg-PSZ) and zirconiatoughened alumina (ZTA). 


\subsection{Zirconia-Based Dental Posts}

The requirement for more esthetic posts, especially under all ceramic restorations, has started the development of new post materials (Fig. 1). In situations where all-ceramic restorations are used for restoring anterior teeth, metal posts may result in unfavorable esthetic results, such as a grey discoloration of translucent all-ceramic crowns and the surrounding gingival margin [8]. Additionally, corrosive reactions with prefabricated posts may cause complications involving the surrounding tissues and oral environment, including a metallic taste, oral burning, sensitization, oral pain, and other reactions [9]. These concerns have led to the development of white or translucent posts made of zirconia and other ceramic materials.

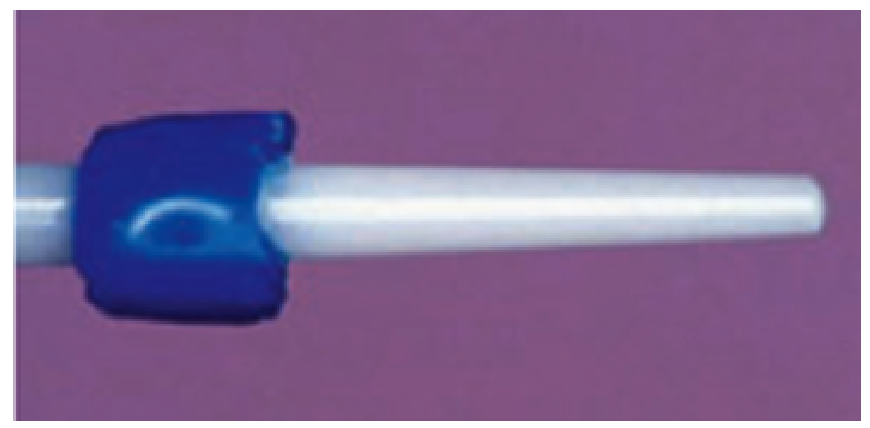

Fig. (1). Zirconia-based dental posts (From Koutayas et al.: Eur J Esthetic Dent, 2009; 4: 348-380.)

A number of researchers have introduced stabilized zirconia ceramic for the fabrication of post systems $[8,10]$, because they have higher strength and fracture toughness than other ceramics. Zirconia posts are available as smooth, tapered and parallel, or tapering at apex and parallel at the coronal aspect. They are rounded at the apical zenith to minimize stress concentration at the root apex.

Other varieties include polyester with $65 \%$ zirconium fibers, with lower Young's modulus and stiffness compared with pure zirconia, but without compromising the advantageous light transmission properties [11]. Zirconia posts which can be used with both direct and indirect techniques, are highly biocompatible, radiopaque, and have excellent light transmission via both the root and coronal restoration.

Kakehashi et al. [12] experimented with zirconia ceramic post clinically and reported that the zirconia post showed a high success rate. Likewise, Paul and Werder [13] investigated zirconia posts and observed good clinical success of zirconia posts with direct composite cores after a mean clinical service of 4.7 years.

The mechanical properties of zirconia posts were tested in in vitro study by Kwiatkowski and Geller [14]. Their results demonstrated that the zirconia posts had higher strength compared to those reported for other all ceramic post and cores.

Zirconia posts also offer possible advantages with respect to esthetics and biocompatibility [15], but have some limitations. They are stiff without any ductility; therefore, difficulties can be encountered when they are in small sizes and when retreatment is necessary [16]. Dietschi et al. [17] reported that the zirconia posts have poor resin-bonding capabilities into radicular dentine after dynamic loading and thermocycling. Likewise, the zirconia ceramic posts showed lower retention values compared to serrated metal posts [15]. Butz et al. [18] showed that zirconia ceramic posts have poor retention into resin cores.

\subsection{Zirconia-Based Crown and Bridge}

The fabrication of zirconia frameworks of either presintered or highly isostatic pressed zirconia for crown and bridge has also been employed [19, 20], as shown in Fig. (2). Zirconia frameworks offer new perspectives in metal free fixed partial dentures and single tooth reconstructions because of zirconium's high flexural strength of more than $900 \mathrm{MPa}$ and showed good first clinical results [21].

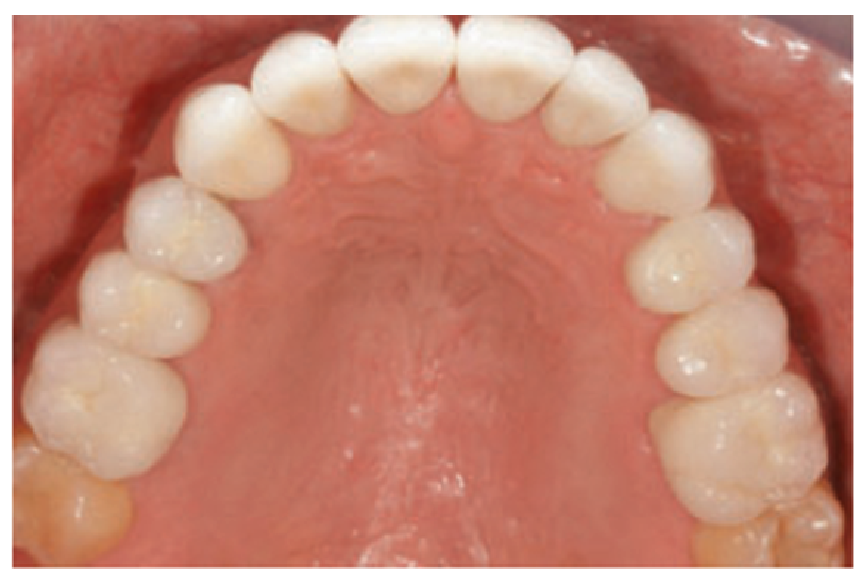

Fig. (2). Zirconia-based frameworks (From Koutayas et al.: Eur J Esthetic Dent, 2009; 4: 348-380).

Tinschert et al. [22] compared survival time of different metal-free core for three unit fixed prostheses and reported that zirconia-ceramic with alumina oxide had the highest initial and most favorable long-term strength. Sailer et al. [23] investigated 58 zirconia bridges fabricated by the direct ceramic machining system clinically. Their results exhibited a survival rate of $84 \%$ in a period of 3.5 years. Minor porcelain chipping was reported in $11 \%$ of the bridges. Tinschert et al. [24] fabricated 65 zirconia bridges fabricated with the DCSPresident ${ }^{\mathbb{B}}$ system. He and his colleagues observed the zirconia bridges for a mean period of three years and reported a small chipping of the veneering material in $6 \%$ of the bridges, which showed a cumulative survival rate of $86 \%$.

\subsection{Zirconia-Based Implant Abutments}

As a result of utilizing the zirconia ceramics for the fabrication of tooth-supported restorations, this encouraged the clinicians to extend its application for implant-supported restorations (Fig. 3).

Utilizing zirconia as implant-supported restorations is due to the higher toughness and the lower modulus of elasticity of zirconia. In stabilized and transformationtoughened forms, zirconia provides some advantages over alumina in order to solve the problem of alumina brittleness and the consequent potential failure of implants [25]. These abutments are distinguished by their tooth-matched color, their good tissue compatibility, and their lower plaque accumulation [26-29]. 


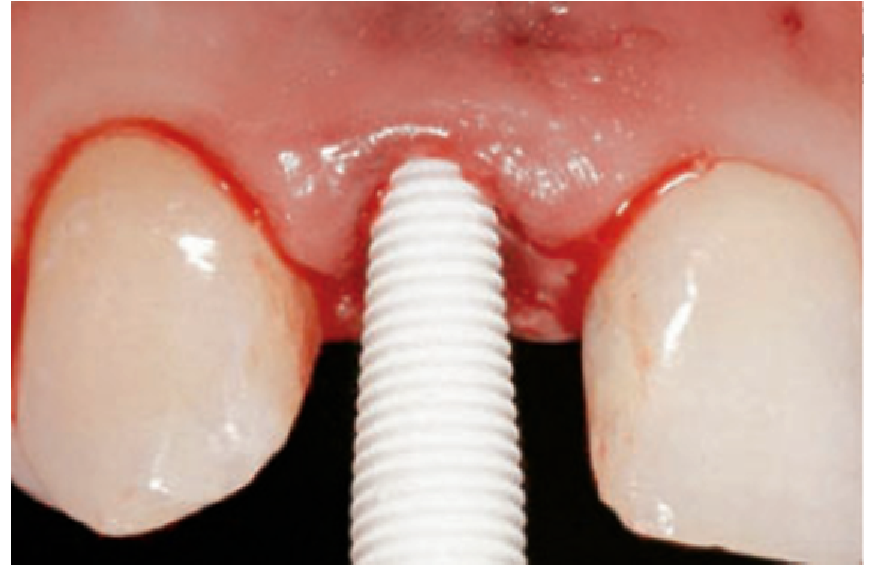

Fig. (3). Zirconia-based implant (From Koutayas et al:: Eur J Esthetic Dent, 2009; 4: 348-380).

Yildirim et al. [29] compared in their in vivo study 30 zirconia abutments with 51 alumina abutments. They found cumulative survival rates of $100 \%$ and $98.1 \%$ for each group of implant abutments respectively for an observation period of 28 months. In a prospective study with an observation period of 4 years, Glauser et al. [30] showed also a cumulative survival rate of $100 \%$ for 53 zirconia abutments. Kohal and Klaus [31] presented in the literature the first clinical case of an all-ceramic custom-made zirconia implant-crown system, which was used for the replacement of a single tooth. Volz and Blaschke [32] also published the case report of a patient with metal sensitivities who received eight custom-made zirconium dioxide implants restored with metal-free zirconia crowns. In both of the cases that were mentioned above, a successful osseointegration was obtained.

Butz et al. [33] compared unprepared titanium-reinforced zirconia and pure alumina abutments for their outcome under fatigue and static loading. Their results exhibited that titanium-reinforced zirconia abutments showed similar behavior as metal abutments. The authors recommended using titanium-reinforced zirconia abutments as an aesthetic alternative for the restoration of single implants in the anterior region. Nguyen et al. [34] examined the performance of various implant-zirconia abutment combinations under fatigue load in a vitro. They reported that rotational load fatigue testing performance of zirconia abutments is dependent on the abutment diameter.

Nevertheless, a number of clinical studies exhibited the high reliability of zirconia as abutment as well as framework material for implant-borne crowns and fixed dental prostheses. However, the clinical success of zirconia based implant is an obstacle by veneering porcelain fractures. The zirconia fractures are due to technical complication [35-37]. Additionally, long-term stability of zirconia is questionable. Therefore, the replacement of titanium implant by zirconia implant is controversial [38, 39]. Recently, Guess et al. [40] reviewed the utility of zirconia in fixed implant prosthodontics. They found that clinical long-term success of zirconia in fixed implant prosthodontics is questionable as a result to fracture of the veneering ceramics and the susceptibility of zirconia to aging. Due to scarcity of clinical studies available, the authors suggested evaluating the performance of zirconia abutments and implant-supported fixed restorations before recommending it for using in daily private practice.

\subsection{Zirconia-Based Esthetic Orthodontic Brackets}

Besides the dental applications that were mentioned previously, zirconia has also been applied for the fabrication of esthetic orthodontic brackets [6]. Polycrystalline zirconia brackets, which reportedly have the greatest toughness amongst all ceramics, have been offered as an alternative to alumina ceramic brackets [41]. They are cheaper than the monocrystalline alumina ceramic brackets but they are very opaque and can exhibit intrinsic colors making them less aesthetic. Good sliding properties have been reported with both stainless steel and nickel-titanium archwires along with reduced plaque adhesion, clinically acceptable bond strengths and bond failure loci at the bracket/adhesive interface [42]. However, Keith et al. [6] found no significant advantage of zirconia brackets over polycrystalline alumina brackets with regard to their frictional characteristics.

\section{AGEING OF ZIRCONIA}

Under certain manufacturing conditions or more severe environmental conditions of moisture and stress, the resulting zirconia may transform more aggressively to the monoclinic phase with catastrophic results as shown in Fig. (4). All transitions which occurred between the different crystalline reticulations are due to the stress applied on the zirconia surface, and this produces a volumetric change in the crystal. Such a "high metastability" is obviously undesirable for medical implants. This mechanical property degradation in zirconia, due to the progressive spontaneous transformation of the metastable tetragonal phase into the monoclinic phase, is known as "ageing" of the material [4345].

A slow transformation as mentioned previously occurs when Y-TZP comes in contact with water or vapor [44], body fluid or during steam sterilization [46], which leads to surface damage (Fig. 5). Non-aqueous solutions with a single-pair electron orbital opposite to a proton donor site can also destabilize Y-TZP, causing strength degradation $[44,45]$.

This rapid low temperature degradation mechanism was described by several studies [46, 47]. Sato et al. [45] postulated that the reaction of water with the $\mathrm{Zr}-\mathrm{O}-\mathrm{Zr}$ at the crack tip and the formation of Zirconium hydroxides accelerate crack growth of pre-existing flaws and promote the T-M phase transition.

The increase in monoclinic phase leads to a reduction in strength, toughness and density, followed by micro and macro cracking of the material [47]. Surface degradation of the material during low temperature aging involves roughening, increased wear and microcracking, grain pullout, generation of particle debris, and possible premature failure [48]. Surface elevations take place most likely because of the more voluminous M-phase transformed particles [45]. Craters have also been observed as a result of worn out monoclinic spots on the degraded surface of the material [48]. The strength degradation level varies between TZP ceramic because aging behavior is related to the differences in equilibrium within the microstructural parameters, such as yttrium concentration and distribution, 


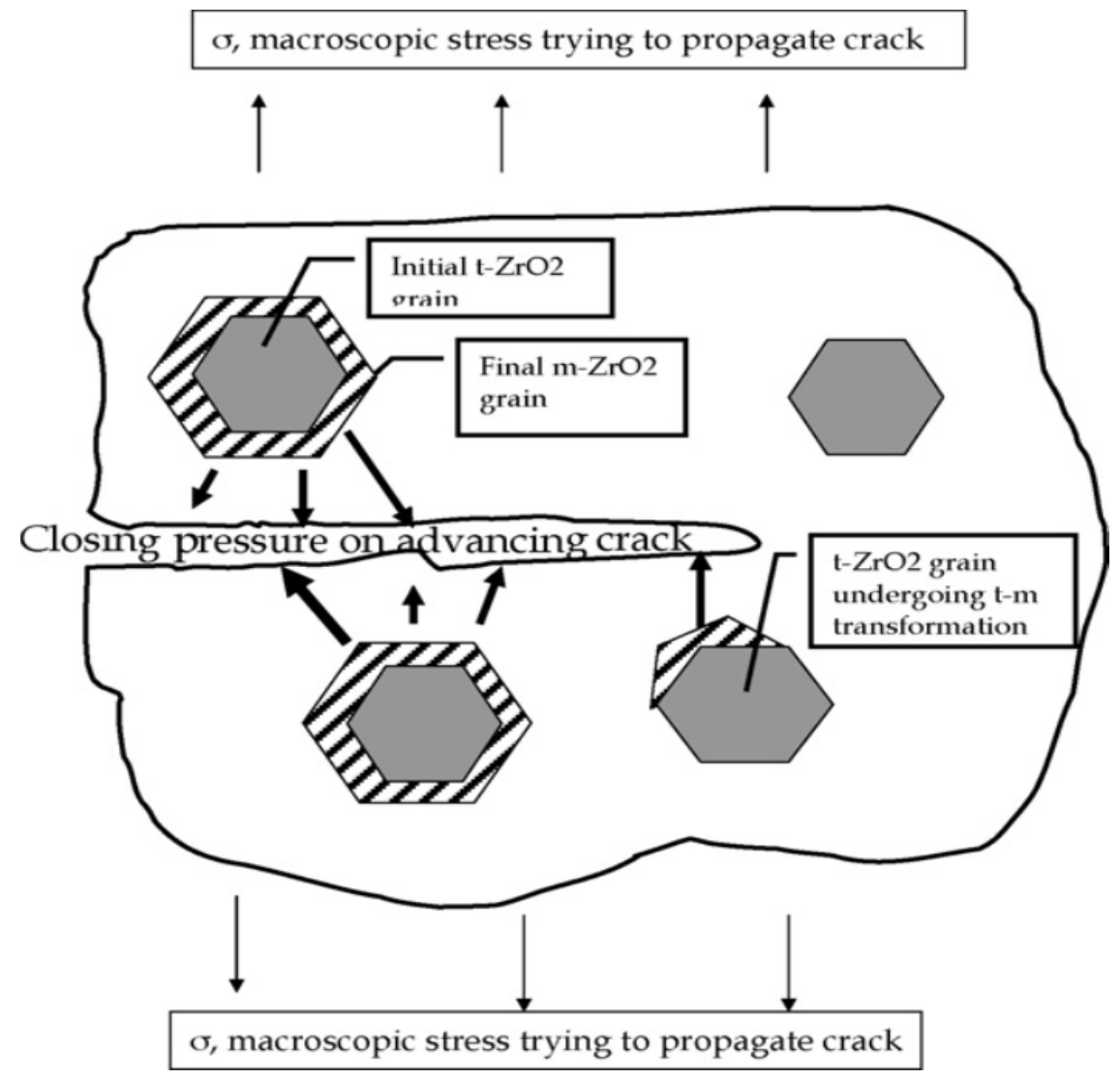

Fig. (4). "Schematic representing how the t-m transformation of $\mathrm{ZrO}_{2}$ increases fracture toughness. When a part containing metastable t- $\mathrm{ZrO}{ }_{2}$ is subject to a remote macroscopic tensile stress, the stress intensification due to the presence of a crack tip is sufficient to transform some tzirconia grains to the monoclinic form. Since this transformation entails a volumetric expansion which is constrained by the surrounding materials, the net result is compressive stress acting on the surfaces of the crack, whose propagation is thus hindered" (From Lughi and Sergo: Dent Mater, 2010; 26: 807-820).

grain size, flaw population, duration of exposure to aging medium, loading of the ceramic restoration, and manufacturing processes $[45,46,48]$.

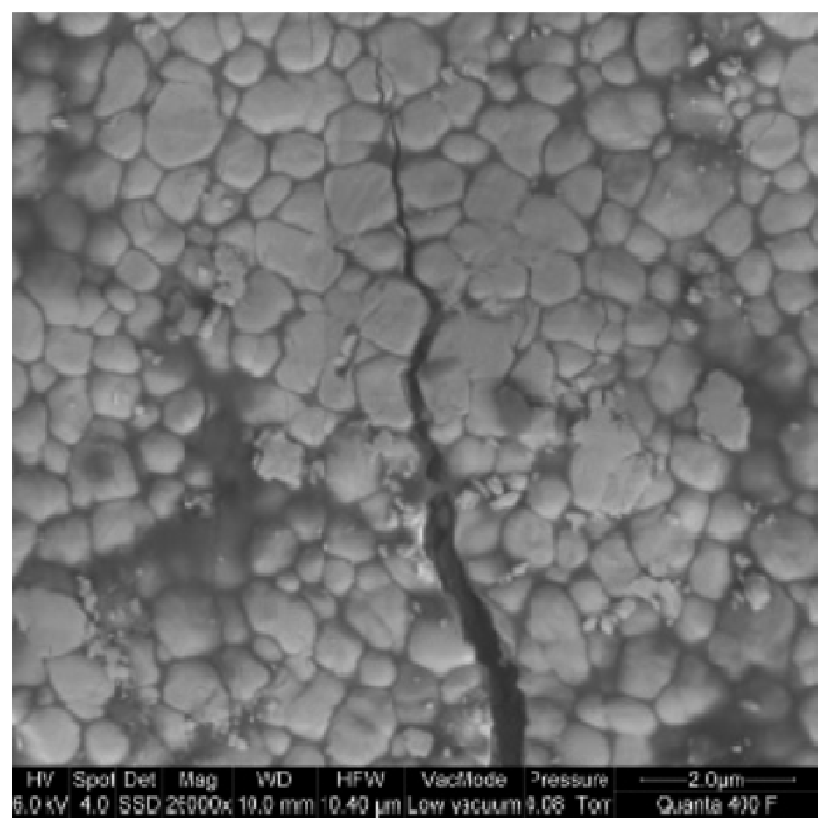

Fig. (5). Zirconia surface: grain size and crack propagation.
Reduction in grain size and/or increase in concentration of stabilizing oxides can reduce the transformation rate. However, reducing the size of grains too much may lead to the loss of "metastability", and increasing the concentration of stabilizing oxide above $3.5 \mathrm{~mol} \%$ may allow the nucleation of significant amounts of the stable cubic phase $[49,50]$. Lughi and Clarke [51-53] showed that in zirconia thermal barrier coatings ( $3 \mathrm{Y}-\mathrm{TZP}$ and 4.5Y-TZP) obtained by electron-beam deposition; significant amounts of monoclinic (up to $100 \%$, depending on the processing) appear only after only few months in laboratory air at room temperature. Additionally, Sergo [54] showed that up to $25 \%$ monoclinic can form at room temperature after only 6 years in 3Y-TZP zirconia/alumina laminates. It has been shown that zirconia loses about $10-50 \%$ of its strength due to aging and permanent loading [55].

\section{FUTURE OPPORTUNITIES IN ZIRCONIA} APPLICATION

\subsection{Zirconia Toughened Alumina}

The alumina-zirconia nanocomposites were introduced and had high resistance to crack propagation, which may offer the option to improve lifetime and reliability of ceramic joint prostheses $[55,56]$. According to De Chevalier et al. [57] and De Aza et al. [58], the possibility to synthesis 
alumina-zirconia nanocomposites has been evidenced by refining powder processing using a new colloidal processing synthesis route.

These new composites can exhibit not only a greater toughness that the monolithic materials previously mentioned, but more important, a greater threshold for the stress intensity factor, under which crack propagation does not take place. This threshold represents an intrinsic property for a given material that gives information of its mechanical behavior in a more realistic way than the widely used toughness, which means only fast crack growth [58, 59]. Although there are relatively low contents of zirconia $(10 \%$ in volume) in this composite, they show similar hardness values as that of alumina and are not susceptible to the hydrothermal instability observed in some cases of stabilized zirconia bioceramics (low temperature degradation) as reported by De Aza et al. [56].

The current laboratory and clinical trials, regarding zirconia implants, as well as zirconia based all-ceramic crowns and fixed partial dentures, are encouraging and promising so far, presenting that this new ceramic material could offer optimal basis for an esthetical restoration of missing teeth.

\subsection{Fabrication Process: Computer-Aided Design and Computer Aided Manufacturing}

For over three decades, evidence to support the validity of oral implants as a treatment option to replace missing teeth has been accumulating. The impressive performance of oral implants has motivated manufacturers and researchers to propose more innovative and convenient treatment protocols. More recently, one of the major developments in implant prosthodontics has been the adoption of engineering principles in the form of computer-aided design and computer aided manufacturing (CAD/CAM) to construct implant prosthesis [60-62].

Implant $\mathrm{CAD} / \mathrm{CAM}$ abutments and frameworks have been reported to be consistently better fitting than conventional cast components [63]. Likewise, the rotational freedom for $\mathrm{CAD} / \mathrm{CAM}$ abutments was reported to be less than $3^{\circ}$ regardless of abutment materials [64]. With implant frameworks, CAD/CAM production has been reported to be at least as accurate as the most accurate implant framework fabrication method and with a tendency to provide the most consistent outcome [65].

With implant abutments, when comparing the fracture resistance of titanium and zirconia abutments in vitro, titanium abutments have been found to be more durable [6667]. It was also found, however, that zirconia abutments were durable enough to withstand an applied occlusal load in the range of $300-460 \mathrm{~N}$ [68-71].

Zirconia abutments and frameworks benefit from full customization as this will ensure minimal zirconia adjustment and maximal material bulk for durability. Kohal et al. found that modifying the zirconia stock abutments with a diamond bur caused a decrease in the fracture strength [72]. Since CAD/CAM produces zirconia workpieces that require no subsequent alteration, unnecessary weakening is avoided. Maximal abutment and framework thickness are desirable and increase the fracture resistance. Following retrieval of fractured zirconia abutments, Aboushelib and Salameh observed that 2 out of 5 abutments are fractured due to over reduction of the axial walls [73]. Further, Nguyen et al. reported that wider CAD/CAM abutments are less likely to fracture than narrower abutments [74]. Similarly, Ohlmann et al. found that thickened zirconia frameworks exhibited higher fracture resistance [75].

\subsection{Functionally Graded Concept}

The development and selection of biocompatible, longlasting, direct-filling tooth restoratives and indirectly prosthetic materials capable of withstand the aggressive environment of the oral cavity, have been a challenge for practitioners of dentistry since the beginning of dental practice.

The concept of functionally graded materials (FGM) has been conceived as a new material design approach to improve performance compared to traditional homogeneous and uniform materials [76]. The concept of FGM has been conceived as a new material design approach to improve performance compared to traditional homogeneous and uniform materials [76]. Ceramics typically exhibit high hardness, low density and weight, brittleness, and excellent high-temperature fracture, creep, corrosion, radiation, wear, and thermal shock resistance. On the other hand, metals are typically ductile, have high tensile strength, high toughness, and high density. Metal-ceramic FGMs can also be designed to take advantage of the heat and corrosion resistance of ceramics and the mechanical strength of metals [77-80].

The transition profile between the two materials must be designed in order to achieve the desired function. This makes the FGM a new class of materials, diverse from conventional homogeneous composite.

Development of functionally graded biomaterials for implants for medical and dental applications has been reported [77-85]. FGM allows the integration of dissimilar materials without formation of severe internal stress and combines diverse properties into a single material system.

The development of FGM concept has its origin in the sophisticated properties which arise from materials in nature, such as and bones [86] and teeth [87]. For instance, the design of a bone with a change from dense, stiff external structure (the cortical bone) to a porous internal one (the spongy bone) demonstrates that functional gradation has been utilized by biological adaptation [86]. This bone's structure reflects a biologic evolution and optimizes the material's response to external loading. Thus, optimized structure for an artificial implant should show similar gradation. The same trend has been observed in the development of functionally graded dental implants with the introduction of surface coatings, porosity gradients and composite materials made essentially of metal and ceramics (e.g. hydroxyapatite), which aimed to improve the implant performance in terms of biocompatibility and stress distribution [88, 89].

Similarly, inspired by the microstructure and mechanical properties of natural teeth, several methods were proposed to mimic the DEJ using synthetic materials. The functionally graded glass/zirconia/glass structure has been reported as alternative for homogeneous zirconia [90]. The coating of 
the top and bottom of a pre-sintered Y-TZP with a slurry of glassy powder results in an increased damage resistance, translucency, and will also allow etching and silane application for reliable bonding mechanisms. Huang et al. [81] added bioinspired FGM layer between the zirconia dental ceramic and the dental cement and investigated the effects of the functionally graded layer on the stress in the crown and its surrounding structures. From their results, the functionally graded layer was shown to promote significant stress reduction and improvements in the critical crack size. From their study, they concluded that the low stress concentrations were associated with the graded distributions in the dentin-enamel junction. Subsequently, Niu et al. [85] also showed similar reductions in stress concentrations in simulations using a bio-inspired functionally graded material layer. Their experimental work demonstrated the processing of such functionally graded multi-layers and the increased critical loads in dental multilayer structures with FGM structures.

Recently, Abu Kasim et al. [91] patented three types of multilayered composite materials that were produced using powders of zirconia $\left(\mathrm{ZrO}_{2}\right)$, alumina $\left(\mathrm{Al}_{2} \mathrm{O}_{3}\right)$, hydroxyapatite (HA), and titanium (Ti) to develop newly designed functionally graded dental post. Likewise, Abu Kasim et al. [92] also investigated the stress distribution of a newly designed functionally graded dental post which consisted of multilayer design of $\mathrm{ZrO}_{2}$-Ti-HA and was compared to posts fabricated from homogeneous material such as titanium and zirconia. They reported that this new dental post exhibited several advantages in terms of stress distribution compared to posts fabricated from homogeneous material. The stress and strain distribution at the post-dentine interface of FGDP was better than that of homogenous posts.

\section{RESIN CEMENT ADHESION TO Y-TZP CERAMIC}

The clinical success of cemented restorations has been evaluated by measuring marginal fit and microleakage for many years [93]. In the case of all-ceramic restorations, microleakage has been correlated with the loss of the integrity of the bond to tooth structure, which has been associated with other problems such as secondary caries, postoperative sensitivity, pulpal inflammation, staining and plaque accumulation due to the clinically undetectable passage of bacteria, fluids, molecules or ions between tooth structure and the cemented restoration.

The high strength of the zirconia framework may allow for adhesive bonding or conventional cementation. Since there is a notable problem with chemical bonding with resin to Y-TZP as it is an inert, nonreactive and complex surface with $\mathrm{Zr}$ atoms on the outer surface, the core treatment before cementation follows the same requirements as the treatment before veneering. The rough surface due to the manufacturing process may promote an additional micromechanical interlocking of the luting agent [94]. In some cases, for the application of silicating / silanization, good bonding results have been reported [95], but this bond fails with increasing storage time due to hydrolysis [96-98]. Other pre-treatment methods are plasma spray treatment, addition of low fusing porcelain layers [99], tribochemical silica coating [94, 97], or the use of phosphate acid ester monomers $[98,100]$. Nevertheless, sufficient bonding after long term storage was found only for cements that contain phosphate-groups $[100,101]$.

Adhesive resins have been developed significantly during recent years with new product generations $[102,103]$. It is widely accepted that the key factors in successful bonding to teeth are micromechanical entanglements of monomer resins to etched enamel and dentin by hybridization and thus marginal seal can be improved considerably [104, 105]. Numerous studies suggested utilizing a phosphate monomer containing luting resin which provides significantly higher retention of zirconia ceramic crowns than conventional luting cements [106-109].

Bond strength tests have always drawn a lot of scientific attention, and that is also the case with evaluating bond strength of different luting materials to YTZP. It is also well established that the data obtained from different bond strength tests depend on the actual test setup used and that may differ between individual studies. Therefore, the bond strength data substantially vary among different studies. All these interacting variables, i.e. surface pretreatment, silicatizing, silanes, primers and different resins, make direct comparison between different studies very difficult and ultimately irrelevant $[110,111]$.

Recently, selective infiltration etching technique was introduced to improve resin cement bonding to ceramic. In this technique, a specific glass infiltration agent was utilized that is capable of diffusing between the grains and results in nano-inter-grain porosity. After rinsing off this agent, the surface of zirconia can create a nano-mechanical bond with an adhesive resin. Additionally, it was the only method capable of maintaining long-term bond strength values after storing in water for four weeks [112]. The bond strength and interface quality achieved using selective infiltration etching could be further improved with special zirconia primers. Silane coupling agents, i.e. silanes, are not able to directly react with the chemically inert zirconia [113] but are functional with selective infiltration etching surface treatment [112].

\section{CONCLUSIONS}

Application of zirconia in various filed of dentistry has been reviewed. This review also focuses on the development and current status of the zirconia that was based on recent reviews. Methods for the improvement and development of properties of zirconia were based on data reported in the literature and on other studies by the authors.

New methods for fabrication of zirconia developed to design new materials are also reviewed. The new trends for improving the mechanical and/or biological properties are alumina-zirconia nanocomposites, computer aided design and computer aided manufacturing and unitizing functionally graded concept. These new trends in the fabricating of zirconia are expected to improve biological and mechanical performance for zirconia.

Recent progress in the improving in biological and mechanical properties of zirconia is reviewed. Although there was major improvement in the mechanical properties of zirconia, further studies are recommended to confirm their properties. 


\section{CONFLICT OF INTEREST}

The authors confirm that this article content has no conflicts of interest.

\section{ACKNOWLEDGEMENTS}

Declared none.

\section{References}

[1] Piconi C, Maccauro G. Zirconia as a ceramic biomaterial: a review. Biomaterials 1999; 20: 1-25.

[2] Helmer JD, Driskell TD. Research on bioceramics. Symposium on use of ceramics as surgical implants. Clemson University, South Carolina: USA 1969

[3] Qualtrough AJ, Piddock V. Ceramics update. J Dent 1997; 25: 915.

[4] Strub JR, Beschnidt SM. Fracture strength of 5 different allceramic crown systems. Int J Prosthodont 1998; 11: 602-9.

[5] McLean JW. Evolution of dental ceramics in the twentieth century. J Prosthet Dent 2001; 85: 61-6.

[6] Keith O, Kusy RP, Whitley JQ. Zirconia brackets: an evaluation of morphology and coefficients of friction. Am J Orthod Dentofacial Ortho 1994; 106: 605-14.

[7] Hannink RHJ, Kelly PM, Muddle BC. Transformation toughening in zirconia-containing ceramics. J Am Ceram Soc 2000; 83: 46187.

[8] Meyenberg KH, Lüthy H, Schärer P. Zirconia posts: A new allceramic concept for nonvital abutment teeth. J Esthet Dent 1995; 7: 73-80.

[9] Kedici SP, Aksüt AA, Kílíçarslan MA, et al. Corrosion behaviour of dental metals and alloys in different media. J Oral Rehabil 1998; 25: 800-8.

[10] Kwiatkowski S, Geller W. Preliminary consideration of the glassceramic dowel post and core. Int J Prosthodont 1989; 2: 51-5.

[11] Michalakis KX, Hirayama H, Sfolkos J, et al. Light transmission of posts and cores used for the anterior esthetic region. Int J Periodont Restor Dent 2004; 24: 62-9.

[12] Kakehashi Y, Lüthy H, Naef R, et al. A new all-ceramic post and core system: clinical, technical, and in vitro results. Int J Periodont Restor Dent 1998; 18:586-93.

[13] Paul SJ, Werder P. Clinical success of zirconium oxide posts with resin composite or glass ceramic cores in endodontically treated teeth: a 4-year retrospective study. Int J Prosthodont 2004; 17: 5248.

[14] Kwiatkowski S, Geller W. Preliminary consideration of the glassceramic dowel post and core. Int J Prosthodont 1989; 2: 51-5.

[15] Purton DG, Love RM, Chandler NP. Rigidity and retention of ceramic root canal posts. Oper Dent 2000; 25: 223-7.

[16] Asmussen E, Peutzfeldt A, Heitmann T. Stiffness, elastic limit, and strength of newer types of endodontic posts. J Dent 1999; 27: 2758.

[17] Dietschi D, Romelli M, Goretti A. Adaptation of adhesive posts and cores to dentin after fatigue testing. Int J Prosthodont 1997; 10: 498-507.

[18] Butz F, Lennon AM, Heydecke G, et al. Survival rate and fracture strength of endodontically treated maxillary incisors with moderate defects restored with different post-and-core systems: an in vitro study. Int J Prosthodont 2001; 14: 58-64.

[19] Luthardt RG, Sandkuhl O, Reitz B. Zirconia-TZP and alumina-advanced technologies for the manufacturing of single crowns. Eur J Prosthodont Restor Dent 1999; 7:113-9.

[20] Tinschert J, Natt G, Mautsch W, et al. Fracture resistance of lithium disilicate-, alumina-, and zirconia-based three-unit fixed partial dentures: a laboratory study. Int J Prosthodont 2001; 14: 231-8.

[21] Sturzenegger B, Feher A, Lüthy $\mathrm{H}$, et al. Klinische Studie von Zirkonoxidbrücken im Seitenzahngebiet hergestellt mit dem DCMSystem. Acta Med Dent Helv 2000; 5: 131-139.

[22] Tinschert J, Natt G, Mohrbotter N, et al. Lifetime of alumina- and zirconia ceramics used for crown and bridge restorations. J Biomed Mater Res B Appl Biomater 2007; 80: 317-21.

[23] Sailer I, Lüthy H, Feher A, et al. 3-Year clinical results of zirconia posterior fixed partial dentures made by direct ceramic machining (DCM). J Dent Res 2003; 74: 21.
[24] Tinschert J, Natt G, Latzke P, et al. Vollkeramische brücken aus DC-Zirkon-Ein klinisches konzept mit erfolg?. Dtsch Zahnärztl Z 2005; 60: 435-5.

[25] Christel P, Meunier A, Dorlot JM, et al. Biomechanical compatibility and design of ceramic implants for orthopedic surgery. Ann NY Acad Sci 1988; 523: 234-56.

[26] Yildirim M, Edelhoff D, Hanisch O, et al. Ceramic abutments-new era in achieving optimal esthetics in implant dentistry. Int $\mathrm{J}$ Periodont Restor Dent 2000; 20: 81-91.

[27] Scarano A, Di Carlo F, Quaranta M, et al. Bone response to zirconia ceramic implants: an experimental study in rabbits. J Oral Implantol 2003; 29: 8-12.

[28] Tan PL, Dunne JT. An esthetic comparison of a metal ceramic crown and cast metal abutment with an all-ceramic crown and zirconia abutment: A clinical report. J Prosthet Dent 2003; 91: 2158.

[29] Yildirim M, Fischer H, Marx R, et al. In vivo fracture resistance of implant supported all-ceramic restorations. J Prosthet Dent 2003; 90: 325-31.

[30] Glauser R, Sailer I, Wohlwend A, et al. Experimental zirconia abutments for implant-supported single-tooth restorations in esthetically demanding regions: 4-year results of a prospective clinical study. Int J Prosthodont 2004; 17: 285-90.

[31] Kohal RJ, Klaus G. A zirconia implant-crown system: a case report. Int J Periodont Restor Dent 2004; 24: 147-53.

[32] Volz U, Blaschke C. Metal-free reconstruction with zirconia implants and zirconia crowns. Quintessence J Dent Tech 2004; 2 : 324-30.

[33] Butz F, Heydecke G, Okutan M, et al. Survival rate, fracture strength and failure mode of ceramic implant abutments after chewing simulation. J Oral Rehabil 2005; 32: 838-43.

[34] Nguyen HQ, Tan KB, Nicholls JI. Load fatigue performance of implant-ceramic abutment combinations. Int J Oral Maxillofacial Implants 2009; 24: 636-46.

[35] Sailer I, Philipp A, Zembic A, et al. A systematic review of the performance of ceramic and metal implant abutments supporting fixed implant reconstructions. Clin Oral Implants Res 2009; 20(Suppl 4): 4-31.

[36] Nothdurft FP, Pospiech PR. Zirconium dioxide implant abutments for posterior single-tooth replacement: first results. J Periodontol 2009; 80: 2065-72.

[37] Larsson C, Vult von Steyern P, Sunzel B, et al. Allceramic two- to five-unit implant-supported reconstructions. A randomized, prospective clinical trial. Swed Dent J 2006; 30: 45-53.

[38] Chevalier J, Gremillard L, Deville S. Low-temperature degradation of zirconia and implications for biomedical implants. Annu Rev Mater Res 2007; 37: 1-32.

[39] Vagkopoulou T, Koutayas SO, Koidis P, et al. Zirconia in dentistry: Part 1. Discovering the nature of an upcoming bioceramic. Eur J Esthet Dent 2009; 4:130-51.

[40] Guess PC, Att W, Strub JR. Zirconia in fixed implant prosthodontics. Clin Implant Dent Related Res 2012; 14: 633-45.

[41] Kusy RP. Orthodontic biomaterials: from the past to the present. Angle Orthod 2002; 72: 501-12.

[42] Springate SD, Winchester LJ. An evaluation of zirconium oxide brackets: a preliminary laboratory and clinical report. $\mathrm{Br} \mathrm{J}$ Orthod 1991; 18: 203-9.

[43] Cales B, Stefani Y, Lilley E. Long-term in vivo and in vitro aging of a zirconia ceramic used in orthopaedy. J Biomed Mater Res 1994; 28: 619-24.

[44] Ardlin BI. Transformation-toughened zirconia for dental inlays, crowns and bridges: chemical stability and effect of lowtemperature aging on flexural strength and surface structure. Dent Mater 2002; 18: 590-5.

[45] Sato T, Shimada M. Transformation of yttria-doped tetragonal $\mathrm{ZrO}_{2}$ polycrystals by annealing in water. J Am Ceram Soc 1985; 68: 356-9.

[46] Piconi C, Maccauro G. Zirconia as a ceramic biomaterial. Biomaterials 1999; 20: 1-25

[47] Lange, FF DG, Davis BI. Degradation during aging of transformation-toughened $\mathrm{ZrO}_{2}-\mathrm{Y}_{2} \mathrm{O}_{3}$ materials at $25^{\circ} \mathrm{C}$. J Am Ceram Soc 1986; 69: 273.

[48] Chevalier J. What future for zirconia as a biomaterial? Biomaterials 2006; 27: 535-43

[49] Gupta TK, Lange FF, Bechtold JH. Effect of stress-induced phase transformation on the properties of polycrystalline zirconia 
containing metastable tetragonal phase. J Mater Sci 1978; 13: 1464-70.

[50] Theunissen GSAM, Bouma JS, Winnubst AJA, et al. Mechanical properties of ultra-fine grained zirconia ceramics. J Mater Sci 1992; 27: 4429-38.

[51] Lughi V, Clarke DR. Low-temperature transformation kinetics of electron-beam deposited 5 wt.\% yttria-stabilized zirconia. Acta Mater 2007; 55: 2049-55.

[52] Lughi V, Clarke DR. High temperature aging of YSZ coatings and subsequent transformation at low temperature. Surf Coat Technol 2005; 200: 1287-91.

[53] Lughi V, Clarke DR. Transformation of electron-beam physical vapor-deposited $8 \mathrm{wt} \%$ yttria-stabilized zirconia thermal barrier coatings. J Am Ceram Soc 2005; 88: 2552-8.

[54] Sergo V. Room temperature aging of laminate composites of alumina/3 mol\%-yttria-stabilized tetragonal zirconia polycrystals. J Am Ceram Soc 2004; 87: 247-53.

[55] Jung YG, Peterson IM, Kim DK, et al. Lifetime-limiting strength degradation from contact fatigue in dental ceramics. J Dent Res 2000; 79: 722-731.

[56] De Aza PN, De Aza AH, De Aza S. Crystalline bioceramic materials. Bol Soc Esp Ceram V 2005; 44: 135-45.

[57] De Chevalier J, De Aza AH, Fantozzi G, et al. Extending the lifetime of ceramic orthopaedic implants. Adv Mater 2000; 12: 1619-21.

[58] De Aza AH, Chevalier J, Fantozzi G, et al. Crack growth resistance of zirconia toughened alumina ceramics for joint prostheses. Key Eng Mater 2002; 206-13: 1535-8.

[59] De Aza AH, Chevalier J, Fantozzi G, et al. Slow crack-growth behavior of zirconia toughened alumina ceramics processed by different methods. J Am Ceram Soc 2003; 86: 115-20.

[60] Kapos T, Ashy LM, Gallucci GO, et al. Computer-aided design and computer-assisted manufacturing in prosthetic implant dentistry. Int J Oral Maxil Impl 2009; 24: 110-117.

[61] Priest G. Virtual-designed and computer-milled implant abutment. J Oral Max Surg 2005; 63: 22-32.

[62] van Noort R. The future of dental devices is digital. Dent Mater 2012; 28: 3-12.

[63] Yuzugullu B, Avci M. The implant-abutment interface of alumina and zirconia abutments. Clin Impl Dent Relat Res 2008; 10:113-21.

[64] Vigolo P, Fonzi F, Majzoub Z, et al. An in vitro evaluation of titanium, zirconia, and alumina procera abutments with hexagonal connection. Int J Oral Max Impl 2006; 21: 575-580.

[65] Abduo J, Lyons K, Bennani V, et al. Fit of screw-retained fixed implant frameworks fabricated by different methods: a systematic review. Int J Prosthodont 2011; 24: 207-20,

[66] Att W, Yajima ND, Wolkewitz M, et al. Influence of preparation and wall thickness on the resistance to fracture of zirconia implant abutments. Clin Impl Dent Related Res 2012; 14: 196-20.

[67] Hosseini M, Kleven E, Gotfredsen K. Fracture mode during cyclic loading of implant-supported single-tooth restorations. J Prosthet Dent 2012; 108: 74-83.

[68] Aramouni P, Zebouni E, Tashkandi E, et al. Fracture resistance and failure location of zirconium and metallic implant abutments. J Contemp Dent Pract 2008; 9: 41-8.

[69] Butz F, Heydecke G, Okutan M, et al. Survival rate, fracture strength and failure mode of ceramic implant abutments after chewing simulation. J Oral Rehabil 2005; 32: 838-43.

[70] Att W, Kurun S, Gerds T, et al. Fracture resistance of single-tooth implant-supported all-ceramic restorations after exposure to the artificial mouth. J Oral Rehabil 2006; 33: 3806

[71] Att W, Kurun S, Gerds T. Fracture resistance of single-tooth implant-supported all-ceramic restorations: an in vitro study. J Prosthet Dent 2006; 95: 111-6.

[72] Kohal RJ, Wolkewitz M, Mueller C. Alumina-reinforced zirconia implants: survival rate and fracture strength in a masticatory simulation trial. Clin Oral Impl Res 2010; 21: 1345-52.

[73] Aboushelib MN, Salameh Z. Zirconia implant abutment fracture: clinical case reports and precautions for use. Int J Prosthodont 2009; 22: 616-9.

[74] Nguyen HQ, Tan KB, Nicholls JI. Load fatigue performance of implant-ceramic abutment combinations. Int J Oral Maxillofacial Implants, 2009; 24: 636-46.

[75] Ohlmann B, Marienburg K, Gabbert O, et al. Fracture-load values of all-ceramic cantilevered fpds with different framework designs. Int J Prosthodont 2009; 22: 49-52.
[76] Watanabe Y, Kawamoto A, Matsuda K. Particle size distributions in functionally graded materials fabricated by the centrifugal solidparticle method. Comp Sci Tech 2002; 62: 881-88.

[77] Watari F, Yokoyama A, Omori M, et al. Biocompatibility of materials and development to functionally graded implant for biomedical application. Comp Sci Tech 2004; 64: 893-908.

[78] Hedia HS, Mahmoud NA. Design optimization of functionally graded dental implant. Biomed Mater Eng 2004; 14: 133-43.

[79] Hedia HS. Design of functionally graded dental implant in the presence of cancellous bone. J Biomed Mater Res B: Appl Biomater 2005; 75: 74-80.

[80] Hedia HS. Effect of cancellous bone on the functionally graded dental implant concept. Biomed Mater Eng 2005; 15: 199-209.

[81] Huang M, Rahbar N, Wang R, et al. Bioinspired design of dental multilayers. Mater Sci Eng A 2007; 464: 315-20.

[82] Wang F, Lee HP, Lu C. Thermal-mechanical study of functionally graded dental implants with the finite element method. J Biomed Mater Res A 2007; 80: 146-58

[83] Yang J, Xiang H-J. Three-dimensional finite element study on the biomechanical behavior of an FGBM dental implant in surrounding bone. J Biomech 2007; 40: 2377-85.

[84] Rahbar N, Soboyejo WO. Design of functionally graded dental multilayers. Fatig Fract Eng Mater Struct 2011; 34: 887-97.

[85] Niu X, Rahbar N, Farias S, et al. Bio-inspired design of dental multilayers: experiments and model. J Mech Behav Biomed Mater 2009; 2: 596-602.

[86] Pompe W, Worch H, Epple M, et al. Functionally graded materials for biomedical applications. Mater Sci Eng A 2003; 362: 40-60.

[87] He LH, Swain MV. Enamel-A functionally graded natural coating. J Dent 2009; 37: 596-603.

[88] Sadollah A, Bahreininejad A. Optimum gradient material for a functionally graded dentalimplant using metaheuristic algorithms. J Mech Behav Biomed Mater 2011; 4: 1384-95.

[89] Lin D, Li Q, Li W, et al. Design optimization of functionally graded dental implant for bone remodeling. Comp Part B 2009; 40: 668-75.

[90] Zhang Y, Kim JW. Graded structures for damage resistant and aesthetic all-ceramic restorations. Dent Mater 2009; 25:781-90.

[91] Abu Kasim NH, Madfa AA, Abd Shukor MH, et al. Metal-ceramic dental post. Patent no. WO2013043039 (A2), 2013.

[92] Abu Kasim NH, Madfa AA, Abd Shukor MH, et al. FE Analysis of functionally graded structured dental posts. Dent Mater J 2011; 30: 869-80.

[93] Valandro LF, Della Bona A, Bottino AM, et al. The effect of ceramic treatment on bonding to densely sintered alumina ceramic. J Prosthet Dent 2005; 93: 253-9.

[94] Blatz MB, Martin J, Lang B. In vitro evaluation of shear bond strengths of resin to densely-sintered high-purity zirconium-oxide ceramic after long-term storage and thermal cycling. J Prosthet Dent 2004; 91: 356-62.

[95] Matinlinna JP, Heikkinen T, Ozcan M, et al. Evaluation of resin adhesion to zirconia ceramic using some organosilanes. Dent Mater 2006; 22: 824-31.

[96] Luthy H, Loeffel O, Hammerle $\mathrm{CH}$. Effect of thermocycling on bond strength of luting cements to zirconia ceramic. Dent Mater 2006; 22: 195-200.

[97] Kern M. Bonding to zirconia ceramic: adhesion methods and their durability. Dent Mater 1998: 64-71.

[98] Tsou Y, Yoshida K, Atsuta M. Effects of alumina-sandblasting and adhesive primers on bonding between resin luting agent and zirconia ceramics. Dent Mater J 2006; 25: 669-74

[99] Derand T, Molin M, Kvam K. Bond strength of composite luting cement to zirconia ceramic surfaces. Dent Mater 2005; 21: 115862.

[100] Yoshida K, Tsuo Y, Atsuta M. Bonding of dual-cured resin cement to zirconia ceramic using phosphate acid ester monomer and zirconate coupler. J Biomed Mat Res Part B, Appl Biomat 2006; 77: 28-33.

[101] Wolfahrt M, Lehmann F, Wolfart S, et al. Durability of the resin bond strength to zirconia ceramic after using different surface conditioning methods. Dent Mater 2007; 23: 45-50.

[102] Watanabe I, Nakabayashi N, Pashley DH. Bonding to ground dentin by a phenyl-P self-etching primer. J Dent Res 1994; 73: 1212-20.

[103] van Meerbeek B, Perdigao J, Lambrechts P, et al. The clinical performance of adhesives. J Dent 1998; 26: 1-20. 
[104] van Meerbeek B, DeMunck J, Yoshida Y, et al. Buonocore memorial lecture. Adhesion to enamel and dentin: current status and future challenges. Oper Dent 2003; 28: 215-35.

[105] van Landuyt KL, Snauwaert J, De Munck J, et al. Systematic review of the chemical composition of contemporary dental adhesives. Biomaterials 2007; 28: 3757-85

[106] Atsu SS, Kilicarslan MA, Kucukesmen HC, et al. Effect of zirconium-oxide ceramic surface treatments on the bond strength to adhesive resin. J Prosthet Dent 2006; 95: 430-6.

[107] Wolfart M, Lehmann F, Wolfart S, et al. Durability of the resin bond strength to zirconia ceramic after using different surface conditioning methods. Dent Mater 2007; 23: 45-50.

[108] Tanaka R, Fujishima A, Shibata Y, et al. Cooperation of phosphate monomer and silica modification on zirconia. J Dent Res 2008; 87 : 666-70.
[109] Shahin R, Kern M. Effect of air-abrasion on the retention of zirconia ceramic crowns luted with different cements before and after fastened aging. Dent Mater 2010; 26: 922-8.

[110] Valandro LF, Özcan M, Amaral R, et al. Microtensile bond strength of a resin cement to silica-coated and silanized In-Ceram Zirconia before and after aging. Int J Prosthodont 2007; 20: 70-2.

[111] Mirmohammadi H, Aboushelib MNM, Salameh Z, et al. Innovations in bonding to zirconia based ceramics: Part III. Phosphate monomer resin cements. Dent Mater 2010; 26: 786-92.

[112] Aboushelib MN, Kleverlaan CJ, Feilzer AJ. Selective infiltrationetching technique for a strong and durable bond of resin cements to zirconia-based materials. J Prosthet Dent 2007; 98: 379-88.

[113] Kitayama S, Nikaido T, Takahashi R, et al. Effect of primer treatment on bonding of resin cements to zirconia ceramic. Dent Mater 2010; 26: 426-32.

(C) Madfa et al.; Licensee Bentham Open.

This is an open access article licensed under the terms of the Creative Commons Attribution Non-Commercial License (http://creativecommons.org/licenses/by$\mathrm{nc} / 3.0 /$ ) which permits unrestricted, non-commercial use, distribution and reproduction in any medium, provided the work is properly cited. 